Discussion Paper No. 03-19

\title{
A Comparison Between the Fed and the ECB: Taylor Rules
}

Katrin Ullrich

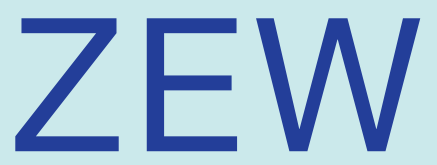

Zentrum für Europäische Wirtschaftsforschung GmbH

Centre for European Economic Research 
Discussion Paper No. 03-19

\title{
A Comparison Between the Fed and the ECB: Taylor Rules
}

\author{
Katrin Ullrich
}

Download this ZEW Discussion Paper from our ftp server:

\section{ftp://ftp.zew.de/pub/zew-docs/dp/dp0319.pdf}

Die Discussion Papers dienen einer möglichst schnellen Verbreitung von neueren Forschungsarbeiten des ZEW. Die Beiträge liegen in alleiniger Verantwortung der Autoren und stellen nicht notwendigerweise die Meinung des ZEW dar.

Discussion Papers are intended to make results of ZEW research promptly available to other economists in order to encourage discussion and suggestions for revisions. The authors are solely responsible for the contents which do not necessarily represent the opinion of the ZEW. 


\section{Non-technical summary}

This paper analyzes the behavior of the Federal Reserve (Fed) and the European Central Bank (ECB) with respect to their interest rate decisions from the beginning of 1999 until mid 2002. Since there was no common monetary policy for the Euro area before 1999, we examine the average central bank behavior of the countries forming the European Monetary Union. To track the behavior of the two central banks we use Taylortype reaction functions which explain the interest rate behavior using the inflation rate and the output gap as the main explanatory variables. We compare the American with the European currency area by searching for similarities and distinctions between the Taylor-type reaction functions of the two central banks. Three main questions are of interest:

(i) Did the reaction function of the Fed and of the ECB (resp. Euro-Area) change over the time period from 1995 to 2002?

(ii) Do the reaction functions show differences in the monetary policy behavior of the Fed and the ECB?

(iii) Is there an interdependence between the reaction functions of the two central banks?

We will estimate Taylor-type policy rules with data on a monthly basis for the ECB and the Fed in order to find answers to these questions. Reaction functions for the time before monetary union from 1995:1 to 1998:12 and for the time from 1999:1 to 2002:8 are analyzed for the Euro area and for the Fed. The reaction functions are compared between the two currency areas and the two time periods. Furthermore, the usual reaction of the interest rate to inflation and the output gap is complemented by additional variables: money growth, exchange rate change and the interest rate of the other currency area. The foreign interest rate is included because there are reasons for a mutual influence like an implicit policy coordination or an international transmission mechanism. 
The estimations show that there are significant differences in the reaction functions of both central banks before and after 1999 and between the two central banks. Because of the limited data available the conclusions must be treated with caution. Nonetheless, for the Euro one of the main findings is a break in the interest rate reaction to inflation with the beginning of the monetary union. Before monetary union, there is a strong reaction of the average interest rate to inflation with a long-run coefficient that exceeds unity. After January 1999 the coefficient falls below unity. Before 1999 we find it difficult to track the behavior of the Fed with a Taylor-type reaction function using our data. After 1999 the Fed seems to attach importance to money growth in setting the interest rates. Our results also suggest that the Fed's policy has an impact on the Euro area policy, especially after 1999. On the other hand, the short-term interest rate of the Euro area is not significant in the reaction function of the Fed. 


\title{
A Comparison between the Fed and the ECB: Taylor Rules
}

\author{
Katrin Ullrich \\ Centre for European Economic Research (ZEW) \\ P.O. Box 1034 43, D-68034 Mannheim, Germany \\ ullrich@zew.de
}

February 2003

\begin{abstract}
This paper analyzes whether Taylor-type policy rules can be used to describe the behavior of the Federal Reserve and the European Central Bank from the beginning of 1999 until mid 2002. Since there was no common monetary policy for the Euro area before 1999, we examine if the average Central Bank behavior of the countries forming the European Monetary Union can be approximated by a single reaction function. We compare the currency areas by searching for similarities and distinctions between the Taylor-type reaction functions of the two central banks. We pay particular attention to the possible influence of one central bank on the behavior of the other one. The simplest method to test this interdependence is to compare the two reaction functions and try to incorporate the decision variable of one central bank into the other central bank's reaction function. The estimations show that there are significant differences in the reaction functions of both central banks before and after 1999 and between the two central banks. The second result is that the Fed seems to influence the ECB but not vice versa.
\end{abstract}

\section{JEL Classification: E58}

Key Words: ECB, Federal Reserve, monetary policy, Taylor rule 



\section{Introduction}

Based on the seminal article by Taylor (1993) there is still a growing research in monetary policy rules. A lot of work has been done for the US central bank and for the Euro area prior to monetary union. For the Euro area, sometimes an artificial Euro area is generated, e.g. Gerlach (1999).

Typically, the existing literature on reaction functions focuses on one central bank without taking into account influences on interest rate decisions from abroad. But there are a few exceptions. Especially the leading role of the Deutsche Bundesbank and its influence on interest rate decisions of other central banks in Europe has attracted some attention (Bergin and Jordá 2002). Also, Clarida, Gali, and Gertler (1998) incorporated the interest rate decisions of the Federal Reserve (Fed) into the reaction function of the Deutsche Bundesbank.

On the other hand, estimated reaction functions for the Fed usually only include domestic economic variables. This may be due to the fact that most of these articles were written before the common European monetary policy was established. It may be the case that an influence of a single (or several) European central banks on the Fed's interest rate decision could simply not be found. But now the currency areas of the US-Dollar and the Euro are of comparable economic power, and the European Central Bank (ECB) determines the monetary policy for the whole Euro area. Thus there is no reason why the ECB's policy should not influence the Fed's decisions and vice versa.

Until now a test of this hypothesis was not possible because of the unavailability of sufficient data on the ECB policy. But in the meantime, the time series needed for estimation of an ECB reaction function based on monthly data seem to be long enough to produce reasonable results which are accessible to a careful interpretation.

Three main questions are of interest: 
(i) Did the reaction function of the Fed and of the ECB (resp. Euro-Area) change over the time period from 1995 to 2002 ?

(ii) Do the reaction functions show differences in the monetary policy behavior of the Fed and the ECB?

(iii) Is there an interdependence between the reaction functions of the two central banks?

We will estimate Taylor-type policy rules for the ECB and the Fed in order to find answers to these questions. As a straightforward approach to search for a mutual impact on monetary policy, we will incorporate the decision variable of one central bank into the other central bank's reaction function and test its significance. In order to increase the length of the ECB time series, we will use an average interest rate of the countries forming the monetary union before 1999 .

This paper is organized as follows. The second section presents some Taylor rule specifications and discusses estimation problems. The third section is an outline of the basic estimation equations followed by the description of the data. The fourth section contains the main results and possible explanations for the findings while the fifth section concludes.

\section{Taylor type rules}

A monetary policy reaction function describes how a central bank sets its policy instrument in response to the economic circumstances. The Taylor rule as a special reaction function is characterized by the response of the interest rate to inflation and the real output gap. Taylor (1993, p.202) assumes the following equation:

$$
i^{*}=\pi+0.5 \bar{y}+0.5(\pi-2)+2
$$

with $i^{*}$ - short term interest rate

$\pi$ - rate of inflation over the previous four quarters

$\bar{y}$ - percent deviation of real GDP from a target. 
The target inflation rate $\pi^{*}$ is assumed to be 2 percent and the equilibrium real interest rate is attributed to be 2 percent. The current inflation rate is used as a proxy for the expected inflation.

Here, a Taylor-type rule is not a commitment of a central bank to a strategy but a description how a central bank sets its instrument in absence of an explicit instrument or targeting rule, the latter proposed for instance by Svensson (2002). Most of the time, the basic Taylor rule gives a surprisingly good description of the behavior of the interest rate. For the examined currency areas figure 1 and 2 show how well the Taylor rule tracks the course of the appropriate interest rate.

Please insert figure 1 and 2 here.

For the Euro area the interest rate resulting from the Taylor rule and the short-term interest rate used in the analysis have a similar movement despite a difference in the level until 1999. ${ }^{1}$ After 1999, the interest rate from the Taylor rule tracks the short-term interest rate not so well anymore. For the US the picture is reversed. Here the track is better after 1999. This is confirmed by the estimations following in the next chapter.

Because a reaction function like this is more or less a rule of thumb, there is no consensus for the appropriate specification of the function. So there are a lot of specifications concerning interest rate smoothing and short-run dynamics of the interest rate, backward- and forward-looking specifications with respective lags and the determination of the measures of inflation and output gap. In the following different specifications are described.

The standard Taylor rule describes the setting of the target interest rate depending on the price gap and the output gap. The respective weights can be estimated by an equation derived from the basic Taylor rule like:

$$
\begin{aligned}
i^{*} & =\gamma \bar{y}+(1+\delta) \pi-\delta \pi^{*}+r \\
& =\alpha+\beta \pi+\gamma \bar{y}
\end{aligned}
$$

\footnotetext{
${ }^{1}$ The difference in the level can arise because of the real interest rate being different than 2 per cent for this time period.
} 
with $\alpha \equiv r-\delta \pi^{*}$ and $\beta \equiv 1+\delta$. So the constant contains the real interest rate and the weighted target inflation rate.

To capture the short-term dynamics of the interest rate we include the lagged interest rate in the equation. There are different explanations for interest rate smoothing (Goodfriend 1990). One possibility is to assume that a central bank is averse to large interest rate movements. Therefore, the interest rate is determined by weighting the interest rate target of the Taylor rule and the lagged interest rate:

$$
i_{t}=\rho i_{t-1}+(1-\rho) i_{t}^{*}+\varepsilon_{t}
$$

Equation 3 is the basis for expanding the number of explanatory variables and changing their time index. Depending on the time index of the variables, often lagged explanatory variables are associated with a backward-looking specification, future and contemporaneous variables with a forward-looking specification. The timing of the variables also has an influence on the interpretation of the reaction function. If the variables are predetermined, the Taylor-type rule is an explicit reaction function whereas if the variables are forward-looking it is an implicit reaction function (Svensson 2002).

Besides inflation and output gap, additional variables can be included into the estimation equation, for instance lagged inflation, money growth, foreign interest rates or real exchange rates (Clarida et al. 1998 or Gerlach and Schnabel 1999). In open economies, the best way to achieve price stability is by targeting "long-run inflation" - a measure of inflation adjusted to remove transitory effects of exchange-rate movements (Ball 2000). But especially the U.S. is not an open economy. The exports of goods and services amount to 10.3 percent of the GDP and the imports to 13.7 percent in 2001 (European Commission 2002, p. 90). For the Euro area, the figures are comparable and amount to 15.5 percent for the exports and 14.8 percent for the imports (computations based on data from the European Central Bank 2003, p. 52,75). However, a term capturing exchange rate effects are included in both estimation equations. 
The first pillar of the ECB's monetary policy framework is the money growth. As the ECB puts it "Inflation is ultimately a monetary phenomenon" (European Central Bank 1999, p. 47). So we add money growth as an explanatory variable. To compare the results a money growth variable is also added to the equation of the Fed.

One focus is to examine a possible interdependence between the reaction functions of the Euro area and the Fed. This will be done by incorporating the interest rate of the other currency area in the estimation as in Greiber and Herz (2000). This will give a first hint whether there is a possible interdependence between the interest rate fixing in the two currency areas. A backward-looking specification looks like (e.g. Kozicki 1999 or Nelson 2000):

$$
\begin{aligned}
i_{t}^{*} & =\alpha+\beta \pi_{t-n}+\gamma \bar{y}_{t-n}+\delta x_{t-n} \\
i_{t} & =\left(1-\sum_{i=1}^{N} \rho_{i}\right) i_{t}^{*}+\sum_{i=1}^{N} \rho_{i} i_{t-i}+\varepsilon_{t} .
\end{aligned}
$$

To simplify the notation all additional variables other than inflation and output gap will be indicated by $x$ in the following specifications of Taylortype rules.

An alternative approach to capture the short-term behavior of the interest rate is to assume an error-correction model similar to Judd and Rudebusch (1998). Here the difference between the actual interest rate and the interest rate resulting from the Taylor rule is closed by an adjustment process of the interest rate. But we exclude the second output gap term of Judd and Rudebusch and allow for lagged values in the $i^{*}$-equation:

$$
\begin{aligned}
\Delta i_{t} & =\rho\left[i_{t-i}-i_{t}^{*}\right]+\zeta \Delta i_{t-i}+\eta_{t} \\
& =\rho\left[i_{t-i}-\alpha-\beta \pi_{t-i}-\gamma \tilde{y}_{t-i}-\delta x_{t-i}\right]+\zeta \Delta i_{t-i}+\eta_{t}
\end{aligned}
$$

Because the transmission of monetary policy takes time a central bank should react to inflation and output gap in the future. This behavior 
will be captured by forward-looking Taylor-type rules (e.g. Gerlach and Schnabel 1999 or Clarida et al. 1998)

$$
\begin{aligned}
i_{t}^{*}= & \alpha+\beta E_{t} \pi_{t+n}+\gamma E_{t} \bar{y}_{t+n}+\delta E_{t} x_{t+n} \\
i_{t}= & \sum_{i=1}^{N} \rho_{i} i_{t-i}+\left(1-\sum_{i=1}^{N} \rho_{i}\right)\left[\alpha+\beta E_{t} \pi_{t+n}+\gamma E_{t} \bar{y}_{t+n}+\delta E_{t} x_{t+n}\right]+\varepsilon_{t} \\
= & \sum_{i=1}^{N} \rho_{i} i_{t-i}+\left(1-\sum_{i=1}^{N} \rho_{i}\right)\left[\alpha+\beta E_{t} \pi_{t+n}+\beta \pi_{t+n}-\beta \pi_{t+n}\right. \\
& \left.+\gamma E_{t} \bar{y}_{t+n}+\gamma \bar{y}_{t+n}-\gamma \bar{y}_{t+n}+\delta E_{t} x_{t+n}+\delta x_{t+n}-\delta x_{t+n}\right]+\varepsilon_{t} \\
= & \sum_{i=1}^{N} \rho_{i} i_{t-i}+\left(1-\sum_{i=1}^{N} \rho_{i}\right)\left[\alpha+\beta \pi_{t+n}+\gamma \bar{y}_{t+n}+\delta x_{t+n}\right]+\nu_{t}
\end{aligned}
$$

with $\nu_{t}=\varepsilon_{t}+(1-\rho)\left[\beta u_{t+n}^{\pi}+\gamma u_{t+n}^{y}+\delta u_{t+n}^{x}\right]$

$$
\begin{aligned}
& u_{t+n}^{\pi}=E_{t} \pi_{t+n}-\pi_{t+n} \\
& u_{t+n}^{y}=E_{t} \bar{y}_{t+n}-y_{t+n} \\
& u_{t+n}^{x}=E_{t} x_{t+n}-x_{t+n}
\end{aligned}
$$

and $E_{t}$ expectations at the beginning of period $t$, or with alternative shortrun dynamics

$$
\begin{aligned}
\Delta i_{t} & =a_{0}+\rho\left[i_{t-m}-i_{t}^{*}\right]+\zeta \Delta i_{t-i}+\eta_{t} \\
& =\rho\left[i_{t-m}-\alpha-\beta \pi_{t+n}-\gamma \bar{y}_{t+n}-\delta x_{t+n}\right]+\zeta \Delta i_{t-i}+\eta_{t}
\end{aligned}
$$

A Taylor-type rule with contemporaneous inflation and output gap can be treated as a special case of a forward-looking Taylor-type reaction function with $n=0$ and is estimated e.g. in Orphanides (2001). If the central bank determines the interest rate at the beginning of the time period, current inflation and output gap are not known but have to be forecasted.

Special problems arise for the forward-looking specification of the Taylortype rule because of measurement errors in the variables. Especially the output gap is affected by revisions. Therefore 2SLS is used for the estimation. The instrument list includes a constant and lagged interest rate, inflation rate, output gap, term structure and exchange rate change. Additionally, in equations containing money growth and the foreign interest rate the respective lagged series are incorporated. 
When the estimated reaction function is backward-looking and only contains lagged variables, there is no problem of endogenous variables. The second problem arises if the contemporaneous interest rate of the other area is included in a forward-looking specification of the estimation equation because there could be a simultaneity problem. If simultaneity applies both equations have to be estimated jointly in a system. But a Hausman specification test assures that there is no problem when estimating both equations separately (see appendix A.1 for the test results).

\section{The Data}

A lot of studies use quarterly data but the decision making of the central banks takes place more often. So monthly data will be used in this analysis. All series but interest rates are seasonally adjusted and are available for the period from January 1994 to July 2002. Since the estimation period starts before the monetary union, it is assumed that for this time period an artificial Euro area is analyzed. This is not uncommon in the literature (e.g. Gerlach and Schnabel 1999).

The three main variables for every currency area are (i) a short-term interest rate, (ii) inflation based on a consumer price index and (iii) the output gap (for further description and data sources see appendix A.2).

The appropriate interest rate is the instrument of the central bank used for monetary policy. Both central banks operate in the money market, but they can only influence the interest rate on the overnight money market directly, not the longer-term interest rates of the money market (Borio 2001). The latter can be influenced over the expectations about the future overnight rate (signalling). The Federal Reserve announces an objective for the federal funds rate, the federal funds target. Therefore the federal funds rate as the operating target is used for estimation (Brüggemann and Thornton 2002). For the European Central Bank the instrument is not that clear. Here the signalling takes place through the interest rates of the main refinancing operations. So the operating target is the Euro Overnight 
Index Average (EONIA) and is therefore used for estimation. Before 1999 the EONIA is replaced by the weighted interbank deposit bid rates.

The ECB has explicitly announced that the inflation of the harmonized consumer price index (HCPI) is the objective for achieving price stability. Therefore this index is used for calculation of the year-to-year inflation rate in percentage points

$$
\pi_{t}=100\left[\log \left(C P I_{t}\right)-\log \left(C P I_{t-12}\right)\right] .
$$

The same calculation is used for the US inflation rate but with the core consumer price index (less food and energy) as a basis. The Fed has no explicit price index announced to fight inflation. Judd and Rudebusch (1998) compare Taylor-type reaction functions, where the inflation rates are based on different price indices. They come to the conclusion that the estimation is not very sensitive with regard to different measures of inflation. Kozicki (1999) comes to the opposite conclusion that the recommendations given by the Taylor rule are not robust to the specification of the inflation and output gap measures. However, we have picked one index and use the core consumer price index in the following regressions.

For the US the rate of the capacity utilization of the US business survey approximates the output gap. For the Euro area there is no similar time series available on a monthly basis. Therefore the output gap is calculated from the industrial production (IP):

$$
\bar{y}_{t}=100\left[\log \left(I P_{t}\right)-\log \left(I P^{*}\right)\right]
$$

with $I P^{*}$ as potential output. The series for potential output is calculated from the series of saisonal adjusted industrial production using a HodrickPrescott-Filter.

In the extended estimations annual money growth of M3 for the Euro area, annual money growth of M2 for the US and annual real effective exchange rate change for both currency areas are used in addition to inflation and output gap. For the Euro area, M3 is chosen because of its three-month moving average is explicitly announced as the first pillar of 
the ECB strategy. In the U.S. the focus is rather on the monetary aggregate M2 (Pakko 1995).

There is a problem with the use of contemporaneous inflation and output gap using historical and therefore revised data. Doing this, one assumes more knowledge about the state of the economy by the central bank than it had at the time of the decisions. Therefore Orphanides (2001) opts for real-time data. But there are no real time data available for the ECB and for the US only with a considerable time lag. Therefore revised data will be used for estimation.

Most of the literature on the estimation of Taylor-type reaction functions does not pay much attention to the properties of the time series. Stationarity of the series is rather assumed than tested (see Florens et al. 2001, p. 4 ). If we test the time series used in the regressions the resulting picture is mixed (for the tests see appendix). For the interest rate of the Euro area (USA), stationarity is rejected at the 5 (10) percent level. Stationarity for the European inflation rate cannot be rejected, but for the US inflation it is. The ADF-test rejects non-stationarity for the output gap of the Euro area, but for the output gap of the US stationarity is rejected. For the change rate of the exchange rate stationarity cannot be rejected for both currency areas. The same is true for the European money growth. But stationarity is rejected for money growth of the US at the 10 percent level. So some of the time series appear to be non-stationary. Therefore the estimation is carried out with the alternative dynamics (equation 6 resp. 9 ) because this approach resembles an error-correction formulation of the equation in question. Nonetheless, if we use the level specification of the estimation equations the long-run coefficients do not change in a significant way.

\section{Estimation Results}

The estimation period contains the time period from January 1995 to June 2002. With the introduction of the Euro and the start of a single monetary 
policy in Europe in January 1999 there could be a structural break in the conduct of the monetary authorities. This is confirmed by a test and therefore we will use dummy variables to capture the effect of changing parameters in the backward-looking equations. Also for the US a change in the instrument setting of the central bank seems to have taken place so in these equations the appropriate dummy variables will be used too. For equations containing the contemporaneous inflation rate, output gap, and additional variables the estimation period is divided in January 1999.

Before 1999 no common monetary institution was responsible for the monetary policy of the Euro area. Therefore it is impossible to estimate a reaction function of a common central bank. On the other hand, the convergence criteria forced the national central banks to keep inflation at a low level. Therefore we will assume that we can explain the behavior of the average interest rate as dependent on Euro-wide economic variables and thus estimable with a Taylor-type reaction function. For a similar investigation using quarterly data see Gerlach and Schnabel (1999).

Especially for forward-looking reaction functions other possible specifications can be imagined. Florens et al. (2001) use an estimation equation leading the inflation 12 months and lagging the output gap one month, Orphanides (2002) uses different leads for inflation and the same leads for the output gap, Clarida et al. (1998) lead inflation 12 months and use the contemporaneous output gap, Clausen and Hayo (2002) use contemporaneous variables. We find that the contemporaneous inclusion of inflation and output gap gives the only reasonable estimation results for the data available.

The following specification for estimating the equations is used (for the estimation results see appendix A.4):

$\Delta i_{t}=a_{0}+a_{1} i_{t-n}+a_{2} \pi_{t+n}+a_{3} \bar{y}_{t+n}+a_{4} x_{t+n}+a_{5} \Delta i_{t-1}+\eta_{t}, \quad n=\{-1,0\}$.

Therefore the long-run reaction coefficients of inflation, output gap and the alternative variable are calculated from the estimated parameters as $-a_{i} / a_{1}, i=2, . ., 5$ and collected in table 1 and 2 , each for lagged and for contemporaneous explanatory variables for the ECB and the Fed. When 
Table 1: Long-run coefficients of Taylor-type rules 1995 - 1998

\begin{tabular}{|l|c|c|c|c|c||c|c|c|c|c|}
\hline & \multicolumn{9}{|c||}{ EMU } & \multicolumn{5}{c|}{ U.S. } \\
\cline { 2 - 12 }$x$ & const. & $i_{t-1}$ & $\pi_{t-1}$ & $\bar{y}_{t-1}$ & $x_{t-1}$ & const. & $i_{t-1}$ & $\pi_{t-1}$ & $\bar{y}_{t-1}$ & $x_{t-1}$ \\
\hline- & 1.40 & 0.22 & $1.61^{*}$ & $0.44^{*}$ & - & $-40.28^{*}$ & 0.18 & 0.24 & $0.54^{*}$ & - \\
$\Delta e$ & $1.45^{*}$ & $0.22^{*}$ & $1.59^{*}$ & $0.43^{*}$ & 0.004 & $-43.01^{*}$ & 0.19 & 0.58 & $0.57^{*}$ & 0.02 \\
$\Delta M$ & $3.28^{*}$ & $0.31^{*}$ & $1.43^{*}$ & $0.26^{*}$ & $-0.33^{*}$ & 2.14 & 0.25 & -0.95 & 0.08 & $-0.26^{*}$ \\
$i^{\#}$ & -4.77 & $0.32^{*}$ & $1.32^{*}$ & 0.21 & $1.23^{*}$ & -22.21 & 0.27 & -0.52 & $0.33^{*}$ & 0.29 \\
\hline$x$ & const. & $i_{t-1}$ & $\pi$ & $\bar{y}$ & $x$ & const. & $i_{t-1}$ & $\pi$ & $\bar{y}$ & $x$ \\
\hline- & $1.97^{*}$ & $0.23^{*}$ & $1.25^{*}$ & $0.29^{*}$ & - & $-36.27^{*}$ & 0.14 & 0.25 & $0.49^{*}$ & - \\
$\Delta e$ & $1.97^{*}$ & 0.23 & $1.25^{*}$ & $0.29^{*}$ & 0.001 & $-32.93^{*}$ & 0.19 & $1.32^{*}$ & $0.42^{*}$ & $0.10^{*}$ \\
$\Delta M$ & $3.42^{*}$ & $0.25^{*}$ & $1.27^{*}$ & $0.24^{*}$ & -0.314 & 4.545 & 0.16 & -1.00 & 0.05 & -0.30 \\
$i^{\#}$ & -4.21 & $0.27^{*}$ & $0.97^{*}$ & 0.08 & 1.225 & -25.19 & 0.17 & -0.20 & $0.36^{*}$ & 0.17 \\
\hline
\end{tabular}

* Underlying parameters in the estimation equation are significant at the 5 percent level.

Table 2: Long-run coefficients of Taylor-type rules 1999 - 2002

\begin{tabular}{|l|c|c|c|c|c||c|c|c|c|c|}
\hline & \multicolumn{9}{|c||}{ EMU } & \multicolumn{6}{c|}{ U.S. } \\
\cline { 2 - 12 }$x$ & const. & $i_{t-1}$ & $\pi_{t-1}$ & $\bar{y}_{t-1}$ & $x_{t-1}$ & const. & $i_{t-1}$ & $\pi_{t-1}$ & $\bar{y}_{t-1}$ & $x_{t-1}$ \\
\hline- & $3.45^{*}$ & 0.15 & 0.04 & $0.60^{*}$ & - & $-51.40^{*}$ & $0.15^{*}$ & 1.38 & $0.67^{*}$ & - \\
$\Delta e$ & 2.42 & 0.05 & -0.24 & 0.61 & $-0.47^{*}$ & $-49.78^{*}$ & $0.18^{*}$ & 1.07 & $0.65^{*}$ & 0.04 \\
$\Delta M$ & $4.28^{*}$ & 0.25 & 0.44 & $0.30^{*}$ & $-0.28^{*}$ & $-38.85^{*}$ & $0.26^{*}$ & $1.19^{*}$ & $0.54^{*}$ & $-0.34^{*}$ \\
$i^{\#}$ & 0.97 & $0.22^{*}$ & $0.65^{*}$ & 0.22 & $0.29^{*}$ & $-48.52^{*}$ & 0.18 & 0.95 & $0.63^{*}$ & 0.18 \\
\hline$x$ & const. & $i_{t-1}$ & $\pi$ & $\bar{y}$ & $x$ & const. & $i_{t-1}$ & $\pi$ & $\bar{y}$ & $x$ \\
\hline- & $2.96^{*}$ & $0.19^{*}$ & 0.25 & $0.63^{*}$ & - & $-55.77^{*}$ & $0.15^{*}$ & $2.25^{*}$ & $0.70^{*}$ & - \\
$\Delta e$ & 2.62 & 0.13 & 0.30 & $0.60^{*}$ & $-0.08^{*}$ & $-50.28^{*}$ & $0.19^{*}$ & 1.34 & $0.65^{*}$ & 0.09 \\
$\Delta M$ & $3.90^{*}$ & $0.27^{*}$ & $0.65^{*}$ & $0.26^{*}$ & $-0.28^{*}$ & $-42.16^{*}$ & $0.20^{*}$ & $1.68^{*}$ & $0.58^{*}$ & $-0.41^{*}$ \\
$i^{\#}$ & 1.40 & $0.22^{*}$ & $0.61^{*}$ & $0.37^{*}$ & $0.20^{*}$ & $-48.09^{*}$ & $0.21^{*}$ & 0.79 & $0.62^{*}$ & 0.52 \\
\hline
\end{tabular}

* Underlying parameters in the estimation equation are significant at the 5 percent level.

the parameters which underlie the long-run coefficients are significant at the 5 percent level, they are marked by an asterisk. To test the significance of the cointegration relationship represented by the coefficient of the lagged interest rate the critical values of Banerjee et al. (1998, p. 276-277) are used.

Estimation period: 1995:1 - 1998:12 For the period from January 1995 to December 1998, it seems that the average interest rates in the later Euro area is tracked reasonably well by a Taylor type rule. This is not true for the Fed. 
For the later Euro area the weight on inflation exceeds unity, except for the equation including the contemporaneous federal funds rate. The weight on the lagged interest rate is relatively low, indicating a slow adjustment process. The coefficient of the output gap is significant and displays values between 0.24 and 0.44 . For the additional variables, only lagged money growth and the lagged federal funds rate are significant. The value for money growth is negative. This confirms the results of Begg et al. for the ECB (2002) that even for the time before the ECB, interest rates cuts are carried out if money growth is strong. This is counterintuitive: one expects increasing interest rates if money growth is strong. The long-run coefficient of the funds rate seems to be unreasonably high with a value of 1.2. If the federal funds rate is significant in the reaction function of the ECB, it has a positive impact on the short-term interest rate but it renders the output gap and the constant insignificant.

The results for the Fed are quite different. In all equations the cointegration relationship is not significant. Furthermore, the only equation that shows a significant coefficient with the expected sign for the inflation rate is the one with the contemporaneous exchange rate change as additional variable: The inflation has a coefficient exceeding one and the output gap has a coefficient of 0.4. For all other equations the parameters are relatively unstable because most of the long-run coefficients do not have the expected size, or even sign and the underlying parameters are not significant. This result differs strongly from Judd and Rudebusch (1998, pp. 9 and 14). They report a coefficient for inflation that exceed unity for the time from 1987:4 to 1997:4. The low value for the constant in the reaction function of the Fed in comparison to the ECB results from a different specification of the output gap. In contrast to the Euro area where the output gap fluctuates around zero the U.S. output gap is defined as the capacity utilization with a full utilization around 80 percent. So the expected value of the output gap is included in the constant. 
Estimation period: 1999:1 - 2002:8 For the second estimation period the picture is reversed. Here a Taylor-type rule tracks the behavior of the Fed better than the behavior of the ECB.

For the ECB, the weight on inflation is lower than unity for all estimated equations. Most of the underlying parameters are not significant at the 5 percent level. A long-run coefficient lower than unity could indicate a destabilizing monetary policy. But the reaction function used here is not conditioned on shocks like demand or technology shocks but on the variables themselves. The use of a reaction function not conditioned on shocks can result in a coefficient smaller than unity depending on the ratio of inflation variance caused by demand to inflation variance caused by technology (Giannone, Reichlin, and Sala 2002, p. 11). A small value of this ratio leads to a small coefficient. Again, the weight on the lagged interest rate is relatively low indicating a slow adjustment process. The output gap is significant most of the time and the long-run coefficient is lower than one, as expected. For this time period the alternative variables are more important than before. There is a significant negative reaction to the exchange rate change and the money growth. Here, the influence of the federal funds rate is much smaller but still significant.

As in the preceding estimation period the results for the U.S. are different in comparison to the ECB reaction functions as well as in comparison to the reaction function of the Fed before 1999. If the parameter of the inflation rate is significant, long-run run stability requires a long-run coefficient of inflation exceeding unity. Again the output gap plays a major role. Its parameters are significant in all estimated specification. From the additional variables only money growth seems to influence the setting of the interest rate by the Fed. Again, we notice a low constant and a slow adjustment process caused by the small coefficient of the lagged interest rate.

Summing up, we find a structural break in the reaction function for both currency areas and a reversal in the goodness of fit before and after the break. On the other hand we find a small adjustment coefficient for both 
curreny areas. Mostly, this is associated with interest rate smoothing or monetary policy inertia. For monthly data, smoothing is well known (Rudebusch 2002). The output gap plays a major role in both reaction functions. The reaction to the output gap is similar across currency areas and time periods.

For the Euro area, there seems to be a considerable change in the reaction of the interest rate to inflation. Before monetary union and in the process of fulfilling the convergence criteria, the estimation confirms the expected reaction to inflation. Other variables play a rather minor role, especially if we assume forward-looking behavior by contemporaneous inclusion of the variables. Inflation loses its major role in the reaction function after monetary union. Instead, the relative importance of the output gap and of other variables like money growth, exchange rate and the foreign interest rate increases.

The Fed's reaction function also displays a different behavior before and after 1999. Here, the change does not concern the reaction of the interest rate to inflation but rather the additional variables. Before January 1999, the Fed reacted rather to the exchange rate change, while it reacted to money growth after January 1999.

Our results suggest a rather one-sided relation between the monetary policy in the two currency areas. The short-term interest rate of the Euro area is not significant in the reaction function of the Fed whereas the federal funds rate is significant in the reaction function of the ECB especially from 1999 on. However, this result has to be treated very cautiously. Bergin and Jordá (2002, p. 11) also find a significant effect of the German monetary policy on the Fed disappearing in a deeper analysis separating timing and direction of monetary policy interdependence.

\section{Concluding Remarks}

In this paper we estimated Taylor-type reaction functions of the Federal Reserve and the European Central Bank with data on monthly basis. Re- 
action function for the time before monetary union from 1995:1 to 1998:12 and for the time from 1999:1 to 2002:8 are analyzed for the Euro area and for the Fed. The reaction functions are compared between the two currency areas and the two time periods. Furthermore, the usual reaction of the interest rate to inflation and the output gap is complemented by additional variables: money growth, exchange rate change and the interest rate of the other currency area. The foreign interest rate is included because there are reasons for a mutual influence like an implicit policy coordination or an international transmission mechanism.

Because of the limited data available the conclusions must be treated with caution. Nonetheless, for the Euro area one of the main findings is a break in the interest rate reaction to inflation with the beginning of the monetary union. Before monetary union, there is a strong reaction of the average interest rate to inflation with a long-run coefficient that exceeds unity. After January 1999 the coefficient falls below unity. Before 1999 we find it difficult to track the behavior of the Fed with a Taylor-type reaction function using our data. After 1999 the Fed seems to attach importance to money growth in setting the interest rates.

Our results also suggest that the Fed's policy has an impact on the Euro area policy, especially after 1999. On the other hand, the short-term interest rate of the Euro area is not significant in the reaction function of the Fed. 


\section{A Appendix}

\section{A.1 Hausman specification test}

Simultaneity between the two reaction functions can potentially occur if the unlagged interest rates of the currency areas are mutually included in their respective reaction function. If simultaneity can be found, the endogenity of the regressors requires an IV estimator for unbiased results. To test for simultaneity we use a Hausman specification test that analyzes if the regressor is correlated with the error term. The starting point are the two Taylor type reaction function for the U.S. and the Euro area:

$$
\begin{aligned}
i_{t}^{e m} & =\rho i_{t-1}^{e m}+(1-\rho) \alpha+(1-\rho) \beta \pi_{t}^{e m} \\
& +(1-\rho) \gamma \bar{y}_{t}^{e m}+(1-\rho) \delta i_{t}^{u s}+\nu_{t}^{e m} \\
i_{t}^{u s} & =\rho^{*} i_{t-1}^{u s}+\left(1-\rho^{*}\right) \alpha^{*}+\left(1-\rho^{*}\right) \beta^{*} \pi_{t}^{u s} \\
& +\left(1-\rho^{*}\right) \gamma^{*} \bar{y}_{t}^{u s}+\left(1-\rho^{*}\right) \delta^{*} i_{t}^{e m}+\nu_{t}^{u s}
\end{aligned}
$$

Due to symmetry, only the reaction function of the ECB is analyzed:

$$
\begin{aligned}
& i_{t}^{e m}=\begin{array}{ll}
\quad & \rho i_{t-1}^{e m}+(1-\rho) \alpha+(1-\rho) \beta \pi_{t}^{e m}+(1-\rho) \gamma \bar{y}_{t}^{e m}+(1-\rho) \delta\left[\rho^{*} i_{t-1}^{u s}\right. \\
& +\left(1-\rho^{*}\right) \alpha^{*}+\left(1-\rho^{*}\right) \beta^{*} \pi_{t}^{u s}+\left(1-\rho^{*}\right) \gamma^{*} \bar{y}_{t}^{u s}+\left(1-\rho^{*}\right) \delta^{*} i_{t}^{e m} \\
& \left.+\nu_{t}^{u s}\right]+\nu_{t}^{e m} \\
= & a_{0} i_{t-1}^{e m}+a_{1}+a_{2} \pi_{t}^{e m}+a_{3} \bar{y}_{t}^{e m}+a_{4}\left[b_{0} i_{t-1}^{u s}+b_{1}+b_{2} \pi_{t}^{u s}+b_{3} \bar{y}_{t}^{u s}\right. \\
& \left.+b_{4} i_{t}^{e m}+\nu_{t}^{u s}\right]+\nu_{t}^{e m}
\end{array} \\
& i_{t}^{e m}= \frac{a_{0}}{1-b_{4}} i_{t-1}^{e m}+\frac{a_{1}}{1-b_{4}}+\frac{a_{2}}{1-b_{4}} \pi_{t}^{e m}+\frac{a_{3}}{1-b_{4}} \bar{y}_{t}^{e m}+\frac{a_{4} b_{0}}{1-b_{4}} i_{t-1}^{u s}+\frac{a_{4} b_{1}}{1-b_{4}} \\
&+ \frac{a_{4} b_{2}}{1-b_{4}} \pi_{t}^{u s}+\frac{a_{4} b_{3}}{1-b_{4}} \bar{y}_{t}^{u s}+a_{4} \nu_{t}^{u s}+\nu_{t}^{e m} \\
& i_{t}^{u s}= \frac{b_{0}}{1-a_{4}} i_{t-1}^{u s}+\frac{b_{1}}{1-a_{4}}+\frac{b_{2}}{1-a_{4}} \pi_{t}^{u s}+\frac{b_{3}}{1-a_{4}} \bar{y}_{t}^{u s}+\frac{b_{4} a_{0}}{1-a_{4}} i_{t-1}^{e m}+\frac{b_{4} a_{1}}{1-a_{4}} \\
&+ \frac{b_{4} a_{2}}{1-a_{4}} \pi_{t}^{e m}+\frac{b_{4} a_{3}}{1-a_{4}} \bar{y}_{t}^{e m}+b_{4} \nu_{t}^{e m}+\nu_{t}^{u s}
\end{aligned}
$$


The estimation of equation 12 results in fitted values of the interest rate $\hat{i}_{t}^{e m}$, used in equation 11 :

$$
\begin{aligned}
i_{t}^{u s}= & \rho^{*} i_{t-1}^{u s}+\left(1-\rho^{*}\right) \alpha^{*}+\left(1-\rho^{*}\right) \beta^{*} \pi_{t}^{u s}+\left(1-\rho^{*}\right) \gamma^{*} \bar{y}_{t}^{u s} \\
& +\left(1-\rho^{*}\right) \delta^{*} \hat{i}_{t}^{e m}+\left(1-\rho^{*}\right) \delta^{*} \hat{\nu}_{t}^{e m}+\nu_{t}^{u s}
\end{aligned}
$$

$H_{0}$ (no simultaneity): no correlation between $\hat{\nu}_{t}^{e m}$ and $\nu_{t}^{u s}$

For an efficient estimation the actual and not fitted values of the interest rate are used.

\begin{tabular}{|c|c|c||c|c|c|}
\hline & \multicolumn{2}{|c||}{ Coefficient } & t-Statistic & & \multicolumn{2}{|c|}{ Coefficient } & t-Statistic \\
\hline dependent variable & \multicolumn{2}{|c||}{$i^{e m}$} & & \multicolumn{2}{c|}{$i^{u s}$} \\
\hline constant & -4.49 & -4.71 & constant & -4.157 & -5.976 \\
$i_{-1}^{e m}$ & 0.72 & 13.9 & $i_{-1}^{u s}$ & 0.926 & 36.63 \\
$\pi^{e m}$ & 0.19 & 3.68 & $\pi^{u s}$ & -0.005 & -0.036 \\
$\bar{y}^{e m}$ & 0.07 & 4.25 & $\bar{y}^{u s}$ & 0.057 & 6.743 \\
$i_{-1}^{u s}$ & -0.00 & -0.15 & $i^{e m}$ & -0.028 & -0.602 \\
$\pi^{u s}$ & 0.44 & 2.66 & RESID1 & 0.004 & 0.043 \\
$\bar{y}^{u s}$ & 0.05 & 4.16 & & & \\
\hline $\bar{R}^{2}$ & 0.96 & & $\bar{R}^{2}$ & 0.98 & \\
\hline
\end{tabular}




\section{A.2 Data Sources}

\section{Time series for the Euro area}

\begin{tabular}{|c|c|c|}
\hline Series & Source & Description \\
\hline short-term interest rate & $\begin{array}{l}\text { European } \\
\text { Central Bank }\end{array}$ & $\begin{array}{l}\text { Weighted rate for the overnight maturity, } \\
\text { calculated by collecting data on unsecured } \\
\text { overnight lending in the euro area provided } \\
\text { by banks belonging to the EONIA panel; } \\
\text { Interbank deposit bid rates to December 1998, } \\
\text { from January } 1999 \text { euro overnight index average }\end{array}$ \\
\hline industrial production & Eurostat & $\begin{array}{l}\text { EU11/12; volume index; } \\
\text { not seasonally adjusted }\end{array}$ \\
\hline consumer price index & Eurostat & $\begin{array}{l}\text { EU11/12 consumer price index all items } \\
\text { (harmonized); } \\
\text { not seasonally adjusted; index }\end{array}$ \\
\hline money growth & $\begin{array}{l}\text { Deutsche } \\
\text { Bundesbank }\end{array}$ & $\begin{array}{l}\text { Monetary aggregate M3; } \\
\text { seasonal adjusted; } \\
\text { annual change; EWU }\end{array}$ \\
\hline exchange rate & OECD & EU11/12; real effective exchange rate; index \\
\hline long-term interest rate & $\begin{array}{l}\text { European } \\
\text { Central Bank }\end{array}$ & $\begin{array}{l}\text { EU11/12 government bond yield - } 10 \text { years; } \\
\text { percentage }\end{array}$ \\
\hline
\end{tabular}

\section{Time series for the U.S.}

\begin{tabular}{|l|l|l|}
\hline Series & Source & Description \\
\hline short-term interest rate & OECD & US federal funds rate; percentage \\
\hline $\begin{array}{l}\text { rate of capacity } \\
\text { utilization }\end{array}$ & OECD & $\begin{array}{l}\text { US Business Survey - } \\
\text { seasonally adjusted; percentage }\end{array}$ \\
\hline consumer price index & $\begin{array}{l}\text { U.S. Department of Labor, } \\
\text { Bureau of Labor Statistics }\end{array}$ & $\begin{array}{l}\text { Consumer Price Index } \\
\text { - All Urban Consumers; } \\
\text { U.S. city average; all items less } \\
\text { food and energy }\end{array}$ \\
\hline monetary aggregate & Eurostat & $\begin{array}{l}\text { money supply M2; not } \\
\text { seasonally adjusted; percentage }\end{array}$ \\
\hline exchange rate & OECD & $\begin{array}{l}\text { real effective exchange rate; index } \\
\text { government composite bond yield - } \\
\text { 10-year; percentage }\end{array}$ \\
\hline long-term interest rate & OECD & \\
\hline
\end{tabular}




\section{A.3 Unit root tests}

\section{Interest rates}

\begin{tabular}{|l|c|c|c|}
\hline & & ZINS_EM & ZINS_US \\
\hline Kwiatkowski-Phillips-Schmidt-Shin test statistic & & 0.524728 & 0.445051 \\
\hline Asymptotic critical values* & $1 \%$ level & 0.739 & \\
& $5 \%$ level & 0.463 & \\
& $10 \%$ level & 0.347 & \\
\hline
\end{tabular}

* Kwiatkowski-Phillips-Schmidt-Shin (1992, Table 1)

\section{Inflation rates}

\begin{tabular}{|l|c|c|c|}
\hline & & D_CPI_EM & D_CPIC_US \\
\hline Augmented Dickey-Fuller test statistic & & -1.615524 & -1.748349 \\
\hline Asymptotic critical values* & $1 \%$ level & -3.505595 & \\
& $5 \%$ level & -2.894332 & \\
& $10 \%$ level & -2.584325 & \\
\hline
\end{tabular}

* MacKinnon (1996) one-sided p-values.

\begin{tabular}{|l|c|c|c|}
\hline & & D_CPI_EM & D_CPIC_US \\
\hline Kwiatkowski-Phillips-Schmidt-Shin test statistic & & 0.265965 & 0.261388 \\
\hline Asymptotic critical values* & $1 \%$ level & 0.739 & 0.216 \\
& $5 \%$ level & 0.463 & 0.146 \\
& $10 \%$ level & 0.347 & 0.119 \\
\hline
\end{tabular}

* Kwiatkowski-Phillips-Schmidt-Shin (1992, Table 1) 


\section{Output gap}

\begin{tabular}{|l|c|c|c|}
\hline & & CAPA_EM & CAPA_US \\
\hline Augmented Dickey-Fuller test statistic & & -4.080697 & 0.233186 \\
\hline Asymptotic critical values* & $1 \%$ level & -2.590910 & -3.504727 \\
& $5 \%$ level & -1.944445 & -2.893956 \\
& $10 \%$ level & -1.614392 & -2.584126 \\
\hline
\end{tabular}

* MacKinnon (1996) one-sided p-values.

\begin{tabular}{|l|c|c|}
\hline & & CAPA_US \\
\hline Kwiatkowski-Phillips-Schmidt-Shin test statistic & & 0.869627 \\
\hline Asymptotic critical values* & $1 \%$ level & 0.739 \\
& $5 \%$ level & 0.463 \\
& $10 \%$ level & 0.347 \\
\hline
\end{tabular}

* Kwiatkowski-Phillips-Schmidt-Shin (1992, Table 1)

\section{Exchange rate change}

\begin{tabular}{|l|c|c|c|}
\hline & & D_ER_EM & D_ER_US \\
\hline Kwiatkowski-Phillips-Schmidt-Shin test statistic & & 0.143638 & 0.154522 \\
\hline Asymptotic critical values* & $1 \%$ level & 0.739 & \\
& $5 \%$ level & 0.463 & \\
& $10 \%$ level & 0.347 & \\
\hline
\end{tabular}

* Kwiatkowski-Phillips-Schmidt-Shin (1992, Table 1)

\section{Money Growth}

\begin{tabular}{|l|c|c|c|}
\hline & & D_M3_EM & D_M2_US \\
\hline Kwiatkowski-Phillips-Schmidt-Shin test statistic & & 0.072102 & 0.141294 \\
\hline Asymptotic critical values* $^{*}$ & $1 \%$ level & 0.216 & \\
& $5 \%$ level & 0.146 & \\
& $10 \%$ level & 0.119 & \\
\hline
\end{tabular}

* Kwiatkowski-Phillips-Schmidt-Shin (1992, Table 1) 


\section{A.4 Estimations}

Basic equation 1995:02 2002:06, backward-looking specification

\begin{tabular}{|c|c|c|c|c|}
\hline & \multicolumn{2}{|c|}{ Euro area } & \multicolumn{2}{c|}{ US } \\
\hline & coefficient & t-value & coefficient & t-value $^{1}$ \\
\hline dependent variable & \multicolumn{4}{|c|}{$\Delta i$} \\
\hline constant*DUM95 & 0.31 & 1.84 & -7.62 & -2.57 \\
constant*DUM99 & 0.52 & 2.72 & -8.21 & -3.29 \\
$i_{-1}$ *DUM95 & -0.22 & -3.05 & -0.18 & -1.67 \\
$i_{-1}$ *DUM99 & -0.15 & -2.22 & -0.15 & -3.75 \\
$\pi_{-1}$ *DUM95 & 0.36 & 2.91 & 0.04 & 0.52 \\
$\pi_{-1}$ *DUM99 & 0.00 & 0.09 & 0.22 & 1.76 \\
$\bar{y}_{-1}$ *DUM95 & 0.09 & 3.44 & 0.10 & 2.63 \\
$\bar{y}_{-1}$ *DUM99 & 0.09 & 2.90 & 0.10 & 3.43 \\
$\Delta_{-1}$ *DUM95 & -0.15 & -1.27 & - & - \\
$\Delta i_{-1}$ *DUM99 & - & - & 0.33 & 2.41 \\
\hline $\bar{R}^{2}$ & \multicolumn{3}{|c|}{0.17} & \multicolumn{2}{c|}{0.58} \\
\hline
\end{tabular}

1 Newey-West HAC Standard Errors \& Covariance (lag truncation=3)

Exchange rate change 1995:02 2002:06, backward-looking specification

\begin{tabular}{|c|c|c|c|c|}
\hline & \multicolumn{2}{|c|}{ Euro area } & \multicolumn{2}{|c|}{ US } \\
\hline & coefficient & t-value ${ }^{1}$ & coefficient & t-value \\
\hline dependent variable & \multicolumn{4}{|c|}{$\Delta i$} \\
\hline constant*DUM95 & 0.33 & 2.73 & -8.277 & -3.99 \\
\hline constant*DUM99 & 0.12 & 0.78 & -9.103 & -3.69 \\
\hline$i_{-1} *$ DUM95 & -0.22 & -3.67 & -0.192 & -2.13 \\
\hline$i_{-1} *$ DUM99 & -0.05 & -1.03 & -0.182 & -3.65 \\
\hline$\pi_{-1} *$ DUM95 & 0.36 & 3.05 & 0.111 & 0.99 \\
\hline$\pi_{-1} *$ DUM99 & -0.01 & -0.25 & 0.195 & 1.28 \\
\hline $\bar{y}_{-1} *$ DUM95 & 0.10 & 3.57 & 0.109 & 4.23 \\
\hline $\bar{y}_{-1} *$ DUM99 & 0.03 & 1.13 & 0.120 & 3.77 \\
\hline$\Delta e_{-1} *$ DUM95 & 0.00 & 0.23 & 0.005 & 0.74 \\
\hline$\Delta e_{-1} *$ DUM99 & -0.02 & -3.86 & 0.008 & 0.65 \\
\hline$\Delta i_{-1} *$ DUM95 & -0.15 & -1.11 & - & - \\
\hline$\Delta i_{-1} *$ DUM99 & -0.33 & -2.13 & 0.330 & 2.78 \\
\hline $\bar{R}^{2}$ & \multicolumn{2}{|c|}{0.28} & \multicolumn{2}{|c|}{0.57} \\
\hline
\end{tabular}

1 Newey-West HAC Standard Errors \& Covariance (lag truncation=3) 
Money growth 1995:02 2002:06, backward-looking specification

\begin{tabular}{|c|c|c|c|c|}
\hline & \multicolumn{2}{|c|}{ Euro area } & \multicolumn{2}{c|}{ US } \\
\hline & coefficient & t-value & coefficient & t-value \\
\hline dependent variable & \multicolumn{4}{|c|}{$\Delta i$} \\
\hline constant*DUM95 & 1.04 & 3.57 & 0.55 & 0.13 \\
constant*DUM99 & 1.09 & 3.41 & -10.1 & -5.85 \\
$i_{-1}$ *DUM95 & -0.31 & -4.22 & -0.25 & -2.85 \\
$i_{-1}$ *DUM99 & -0.25 & -3.19 & -0.26 & -7.43 \\
$\pi_{-1}$ *DUM95 & 0.45 & 3.81 & -0.24 & -1.68 \\
$\pi_{-1}$ *DUM99 & 0.11 & 1.34 & 0.31 & 2.26 \\
$\bar{y}_{-1}$ *DUM95 & 0.08 & 3.12 & 0.02 & 0.50 \\
$\bar{y}_{-1}$ *DUM99 & 0.07 & 2.56 & 0.14 & 7.14 \\
$\Delta M_{-1}$ *DUM95 & -0.10 & -2.97 & -0.06 & -2.25 \\
$\Delta M_{-1}$ *DUM99 & -0.07 & -2.14 & -0.09 & -3.72 \\
$\Delta i_{-1}$ *DUM95 & -0.23 & -2.00 & - & - \\
$\Delta i_{-1}$ *DUM99 & - & - & - & - \\
\hline \multicolumn{7}{|c|}{0.27} & \multicolumn{3}{c|}{0.62} \\
\hline
\end{tabular}

Foreign interest rate 1995:02 2002:06, backward-looking specification

\begin{tabular}{|c|c|c|c|c|}
\hline & \multicolumn{2}{|c|}{ Euro area } & \multicolumn{2}{c|}{ US } \\
\hline & coefficient & t-value $^{1}$ & coefficient & t-value $^{1}$ \\
\hline dependent variable & \multicolumn{4}{|c|}{$\Delta i$} \\
\hline constant*DUM95 & -1.53 & -1.95 & -6.17 & -1.97 \\
constant*DUM99 & 0.22 & 1.22 & -8.80 & -2.84 \\
$i_{-1} *$ DUM95 & -0.32 & -4.86 & -0.27 & -2.23 \\
$i_{-1} *$ DUM99 & -0.22 & -4.97 & -0.18 & -2.61 \\
$\pi_{-1}$ *DUM95 & 0.42 & 3.79 & -0.14 & -0.94 \\
$\pi_{-1}$ *DUM99 & 0.14 & 2.23 & 0.17 & 1.12 \\
$\bar{y}_{-1}$ *DUM95 & 0.06 & 1.77 & 0.09 & 2.36 \\
$\bar{y}_{-1}$ *DUM99 & 0.05 & 1.43 & 0.11 & 2.82 \\
$i_{-1}^{\#} *$ DUM95 & 0.39 & 2.38 & 0.08 & 1.68 \\
$i_{-1}^{\#} *$ DUM99 & 0.06 & 3.14 & 0.03 & 0.52 \\
$\Delta_{-1} *$ DUM95 & -0.12 & -0.87 & - & - \\
$\Delta i_{-1} *$ DUM99 & - & - & 0.33 & 2.49 \\
\hline \multicolumn{3}{|c|}{0.26} & \multicolumn{3}{c|}{0.58} \\
\hline
\end{tabular}

1 Newey-West HAC Standard Errors \& Covariance (lag truncation=3) 


\section{Basic equation 1995:07 1998:12, forward-looking specification}

The following equations are all estimated with TSLS. Instrument list: constant, interest rate, inflation rate, output gap, term structure and exchange rate change with lag 1 to 6 , additionally in equations containing money growth and the foreign interest rate the respective series with lag 1 to 6 .

\begin{tabular}{|c|c|c|c|c|}
\hline & \multicolumn{2}{|c|}{ Euro area } & \multicolumn{2}{c|}{ US } \\
\hline & coefficient & t-value & coefficient & t-value \\
\hline dependent variable & \multicolumn{3}{|c|}{$\Delta i$} \\
\hline constant & 0.46 & 2.47 & -5.31 & -2.61 \\
$i_{-1}$ & -0.23 & -3.28 & -0.14 & -1.67 \\
$\pi$ & 0.29 & 2.54 & 0.03 & 0.53 \\
$\bar{y}$ & 0.07 & 2.12 & 0.07 & 2.88 \\
$\Delta i_{-1}$ & -0.33 & -2.32 & - & - \\
\hline $\bar{R}^{2}$ & \multicolumn{2}{|c|}{0.23} & \multicolumn{2}{c|}{0.11} \\
\hline
\end{tabular}

Exchange rate change 1995:07 1998:12, forward-looking specification

\begin{tabular}{|c|c|c|c|c|}
\hline & \multicolumn{2}{|c|}{ Euro area } & \multicolumn{2}{c|}{ US } \\
\hline & coefficient & t-value & coefficient & t-value \\
\hline dependent variable & \multicolumn{4}{|c|}{$\Delta i$} \\
\hline constant & 0.47 & 2.09 & -6.47 & -3.47 \\
$i_{-1}$ & -0.23 & -2.71 & -0.19 & -2.46 \\
$\pi$ & 0.30 & 2.20 & 0.26 & 2.75 \\
$\bar{y}$ & 0.07 & 2.03 & 0.08 & 3.60 \\
$\Delta e$ & 0.00 & 0.03 & 0.02 & 3.19 \\
$\Delta i_{-1}$ & -0.33 & -2.23 & - & - \\
\hline $\bar{R}^{2}$ & \multicolumn{2}{|c|}{0.21} & \multicolumn{3}{c}{0.28} \\
\hline
\end{tabular}


Money growth 1995:07 1998:12, forward-looking specification

\begin{tabular}{|c|c|c|c|c|}
\hline & \multicolumn{2}{|c|}{ Euro area } & \multicolumn{2}{c|}{ US } \\
\hline & coefficient & t-value & coefficient & t-value $^{1}$ \\
\hline dependent variable & \multicolumn{4}{|c|}{$\Delta i$} \\
\hline constant & 0.86 & 3.00 & 0.76 & 0.16 \\
$i_{-1}$ & -0.25 & -3.53 & -0.16 & -2.13 \\
$\pi$ & 0.32 & 2.77 & -0.16 & -1.01 \\
$\bar{y}$ & 0.06 & 2.03 & 0.01 & 0.19 \\
$\Delta M$ & -0.07 & -1.86 & -0.05 & -1.47 \\
$\Delta i_{-1}$ & -0.35 & -2.53 & - & - \\
\hline $\bar{R}^{2}$ & \multicolumn{2}{|c|}{0.28} & \multicolumn{3}{c|}{0.15} \\
\hline
\end{tabular}

1 Newey-West HAC Standard Errors \& Covariance (lag truncation=3)

Foreign interest rate 1995:07 1998:12, forward-looking specification

\begin{tabular}{|c|r|r|r|r|}
\hline & \multicolumn{2}{|c|}{ Euro area } & \multicolumn{2}{c|}{ US } \\
\hline & coefficient & t-value & coefficient & t-value \\
\hline dependent variable & \multicolumn{4}{|c|}{$\Delta i$} \\
\hline constant & -1.16 & -1.19 & -4.50 & -1.97 \\
$i_{-1}$ & -0.27 & -3.82 & -0.17 & -1.54 \\
$\pi$ & 0.26 & 2.41 & -0.03 & -0.23 \\
$\bar{y}$ & 0.02 & 0.57 & 0.06 & 2.50 \\
$i^{\#}$ & 0.33 & 1.69 & 0.03 & 0.49 \\
$\Delta i_{-1}$ & -0.34 & -2.49 & - & - \\
\hline $\bar{R}^{2}$ & 0.31 & \multicolumn{3}{|c|}{0.09} \\
\hline
\end{tabular}

Basic equation 1999:07 2002:08, forward-looking specification

\begin{tabular}{|c|r|r|r|r|}
\hline & \multicolumn{2}{|c|}{ Euro area } & \multicolumn{2}{c|}{ US } \\
\hline & coefficient & t-value & coefficient & t-value $^{1}$ \\
\hline dependent variable & \multicolumn{4}{|c|}{$\Delta i$} \\
\hline constant & 0.58 & 3.55 & -8.88 & -3.56 \\
$i_{-1}$ & -0.19 & -3.43 & -0.15 & -3.89 \\
$\pi$ & 0.04 & 0.70 & 0.35 & 2.37 \\
$\bar{y}$ & 0.12 & 3.92 & 0.11 & 3.69 \\
$\Delta i_{-1}$ & - & - & 0.31 & 2.23 \\
\hline $\bar{R}^{2}$ & 0.20 & \multicolumn{3}{|c|}{0.70} \\
\hline
\end{tabular}

1 Newey-West HAC Standard Errors \& Covariance (lag truncation=3) 
Exchange rate change 1999:07 2002:08, forward-looking specification

\begin{tabular}{|c|r|r|r|r|}
\hline & \multicolumn{2}{|c|}{ Euro area } & \multicolumn{2}{c|}{ US } \\
\hline & coefficient & t-value & coefficient & t-value \\
\hline dependent variable & \multicolumn{4}{|c|}{$\Delta i$} \\
\hline constant & 0.34 & 1.92 & -9.89 & -4.90 \\
$i_{-1}$ & -0.13 & -2.23 & -0.19 & -4.68 \\
$\pi$ & 0.04 & 0.62 & 0.26 & 1.61 \\
$\bar{y}$ & 0.07 & 2.30 & 0.12 & 5.08 \\
$\Delta e$ & -0.01 & -2.46 & 0.01 & 1.39 \\
$\Delta i_{-1}$ & - & - & 0.33 & 2.81 \\
\hline $\bar{R}^{2}$ & 0.33 & \multicolumn{3}{|c}{0.72} \\
\hline
\end{tabular}

Money growth 1999:07 2002:08, forward-looking specification

\begin{tabular}{|c|r|r|r|r|}
\hline & \multicolumn{2}{|c|}{ Euro area } & \multicolumn{2}{c|}{ US } \\
\hline & coefficient & t-value $^{1}$ & coefficient & t-value \\
\hline dependent variable & \multicolumn{4}{|c|}{$\Delta i$} \\
\hline constant & 1.06 & 4.94 & -8.84 & -5.50 \\
$i_{-1}$ & -0.27 & -5.06 & -0.20 & -7.44 \\
$\pi$ & 0.17 & 2.41 & 0.35 & 2.63 \\
$\bar{y}$ & 0.07 & 3.22 & 0.12 & 6.79 \\
$\Delta M$ & -0.07 & -3.35 & -0.08 & -4.00 \\
$\Delta i_{-1}$ & - & - & - & - \\
\hline $\bar{R}^{2}$ & 0.35 & & 0.76 \\
\hline
\end{tabular}

1 Newey-West HAC Standard Errors \& Covariance (lag truncation=3)

Foreign interest rate 1999:07 2002:08, forward-looking specification

\begin{tabular}{|c|r|r|r|r|}
\hline & \multicolumn{2}{|c|}{ Euro area } & \multicolumn{2}{c|}{ US } \\
\hline & coefficient & t-value & coefficient & t-value \\
\hline dependent variable & \multicolumn{4}{|c|}{$\Delta i$} \\
\hline constant & 0.32 & 1.85 & -10.4 & -4.90 \\
$i_{-1}$ & -0.22 & -4.42 & -0.21 & -4.34 \\
$\pi$ & 0.14 & 2.00 & 0.17 & 0.94 \\
$\bar{y}$ & 0.08 & 2.79 & 0.13 & 5.01 \\
$i_{\#}$ & 0.04 & 2.77 & 0.11 & 1.54 \\
$\Delta i_{-1}$ & - & - & 0.26 & 2.15 \\
\hline $\bar{R}^{2}$ & 0.37 & \multicolumn{3}{|c|}{0.72} \\
\hline
\end{tabular}




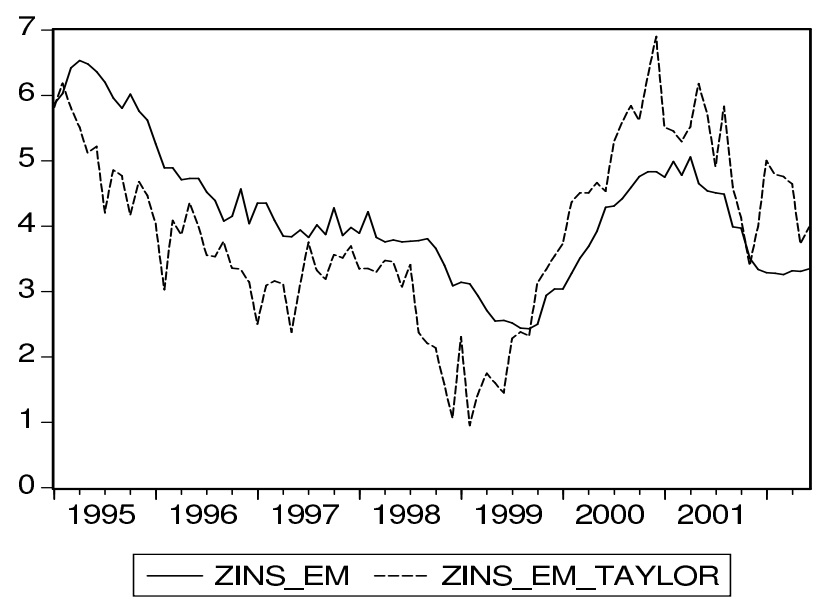

Figure 1: The short-term interest rate ${ }^{b}$ and the interest rate calculated from the basic Taylor rule $i^{*}=\pi+0.5 \bar{y}+0.5(\pi-2)+2=1.5 \pi+0.5 \bar{y}+1$ for the Euro area from 1995:1 to 2002:06.

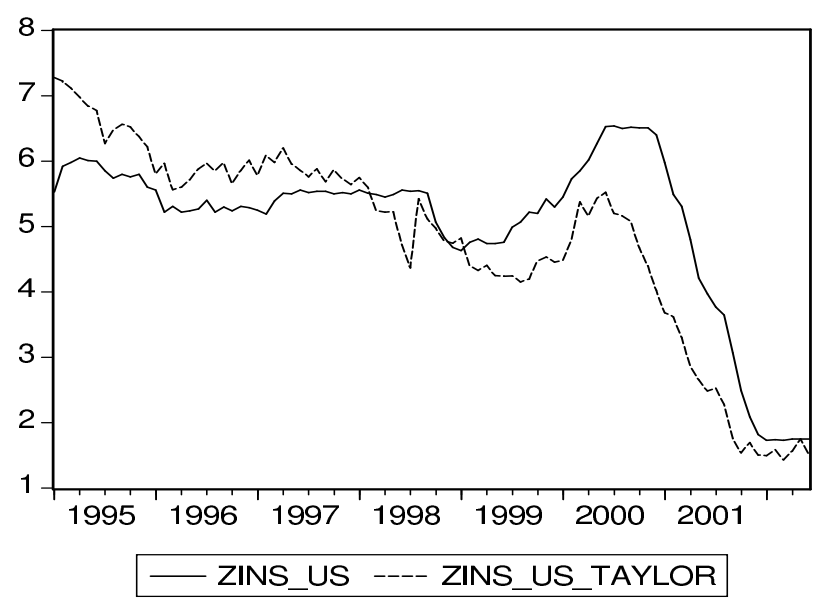

Figure 2: The federal funds rate and the interest rate calculated from the basic Taylor rule $i^{*}=$ $\pi+0.5 \bar{y}+0.5(\pi-2)+2=1.5 \pi+0.5 \bar{y}+1$ for the US from 1995:1 to 2002:6.

${ }^{a}$ Weighted rate for the overnight maturity, calculated by collecting data on unsecured overnight lending in the euro area provided by banks belonging to the EONIA panel. Source: ECB (Interbank deposit bid rates to December 1998, from January 1999 euro overnight index average (EONIA))

${ }^{b}$ Weighted rate for the overnight maturity, calculated by collecting data on unsecured overnight lending in the euro area provided by banks belonging to the EONIA panel. Source: ECB (Interbank deposit bid rates to December 1998, from January 1999 euro overnight index average (EONIA)) 


\section{References}

Ball, L. (2000), Policy Rules and External Shocks, NBER Working Paper Series No. 7910, London.

BanerJee, A., J. J. Dolado, and R. Mestre (1998), Error-Correction Mechanism Tests for Cointefration in a Single-Eruation Framwork, Journal of Time Series Analysis 19(3), 267-283.

Begg, D., F. Canova, A. Fatás, P. D. Graune, and P. R. Lane (2002), Monitoring the European Central Bank (MECB) Update 2002, $C E P R$, London.

Bergin, P. R., and O. Jordá (2002), Measuring Monetary Policy Interdependence, Working Paper, Davis.

Borio, C. (2001), A Hundred Ways to Skin a Cat: Comparing Monetary Policy Operating Procedures in the United States, Japan, and the Euro Area, BIS Paper No. 9, Basel, 1-22.

Brüggemann, I., and D. L. Thornton (2002), Interest Rate Smoothing and the Specification of the Taylor Rule, Working Paper.

Clarida, R., J. Gali, and M. Gertler (1998), Monetary Policy Rules in Practice: Some International Evidence, European Economic Review, 42, 1033-1067.

Clausen, V., and B. Hayo (2002), Monetary Policy an the Euro AreaLessons from the First Years, ZEI Working Paper B 09, Bonn.

European Central Bank (1999), The Stability-Oriented Monetary Policy Strategy of the Euro System, Monthly Bulletin, January 1999, 39-50.

European Commission (2002), Economic Forecasts Autumn 2002, European Economy No. 5.

Europäische Zentralbank (2003), Statistik des EuroWährungsgebietes, Monatsbericht, Januar 2003. 
Florens, C., E. Jondeau, and H. L. Bihan (2001), Assessing GMM Estimates of the Federal Reserve Reaction Function, Working Paper No. 01-04, Univerite Paris XII val de Marne.

Gerlach, S., and G. Schnabel (1999), The Taylor Rule and Interest Rates in the EMU Area, CEPR Discussion Paper No. 2271, London.

Giannone, D., L. Reichlin, and L. Sala (2002), Tracking Greenspan: Systematic and Unsystematic Monetary Policy Revisited, CEPR Discussion Paper No. 3550, London.

Goodfriend, M. (1990), Interest Rates and the Conduct of Monetary Policy, FRBR Working Paper No. 90-6.

Greiber, C., and B. Herz (2000), Taylor Rules in Open Economies, Working Paper, Bayreuth.

Judd, J. P., and G. D. Rudebusch (1998), Taylor's Rule and the Fed: 1970-1997, FRBSF Economic Review No. 3 , 3-16.

Kozicki, S. (1999), How Useful are Taylor Rules for Monetary Policy, Economic Review, Federal Reserve Bank of Kansas City, 5-33.

Kwiatowski, D., Phillips, P. C.B., Schmidt, P., and Shin, Y. (1992), Testing the Null Hypothesis of Stationarity against the Alternative of a Unit Root, Journal of Econometrics 54(1-3), 159-178.

MacKinnon, J. G. (1996), Numerical Distribution Functions for Unit Root and Cointegration Tests, Journal of Applied Econometrics 11(6), 601-618.

Nelson, E. (2000), UK Monetary Policy 1972-97: A Guide Using Taylor Rules, Working Paper No. 120, Bank of England.

Orphanides, A. (2001), Monetary Policy Rules on Real-Time Data, American Economic Review 91(4), 964-985.

PAKko, M. R. (1995), The FOMC in 1993 and 1994: Monetary Policy in Transition, Review of the Federal Reserve Bank of St. Louis 77(2), 3-25. 
Rudebusch, G. D. (2002), Term Structure Evidence on Interest Rate Smoothing and Monetary Policy Inertia, Journal of Monetary Economics 49, 1161-1187.

Svensson, L. E. (2002), What Is Wrong with Taylor Rules? Using Judgment in Monetary Policy Through Targeting Rules, Forthcoming in Journal of Economic Literatur.

TAYlor, J. B. (1993), Discretion versus Policy Rules in Practice, Carnegie-Rochester Conference Series on Public Policy 39, 195-214. 